\title{
Bioactivity of Indigenous Medicinal Plants against the Two-Spotted Spider Mite, Tetranychus urticae
}

\author{
E. Abou-Fakhr Hammad ${ }^{1}$, M. Akkary ${ }^{2}$, N. Saliba ${ }^{3}$, M. Farran ${ }^{1} \&$ S. Talhouk ${ }^{4}$ \\ ${ }^{1}$ Department of Agricultural Sciences, Faculty of Agricultural and Food Sciences, American University of Beirut, \\ Beirut, Lebanon \\ ${ }^{2}$ Debbane Group, DESCO Holding SAL, Beirut, Lebanon \\ ${ }^{3}$ Department of Chemistry, Faculty of Arts and Sciences, American University of Beirut, Beirut, Lebanon \\ ${ }^{4}$ Department of Landscape Design and Ecosystem Management, Faculty of Agricultural and Food Sciences, \\ American University of Beirut, Beirut, Lebanon \\ Correspondence: E. Abou-Fakhr Hammad, Department of Agricultural Sciences, Faculty of Agrcultural and \\ Food Sciences, American University of Beirut, Riad El Solh, Beirut 1107-2070, Lebanon. Tel: 961-(1)-350-000 \\ ext.4493.E-mail: ima27@mail.aub.edu
}

Received: April 13, 2017

Accepted: May 21, $2017 \quad$ Online Published: June 15, 2017

doi:10.5539/jas.v9n7p123

URL: https://doi.org/10.5539/jas.v9n7p123

\begin{abstract}
Forty two methanol extracts and 12 aqueous extracts of 29 indigenous medicinal plant species were tested for their acaricidal bioactivity against the two spotted spider mite, Tetranychus urticae adults at the laboratory. Fourteen methanol plant extracts caused significant mortality in mites. This is the first report for the potential effect on survival of mites for 27 tested endemic plant species. Methanol whole plant extracts (WPEs) of Lotus carmeli, Alchemilla diademata, Eryngium deserlorum and aqueous fruit extracts (FrEs) of Melia azedarach caused toxic effects against the adult mites in the range of $41-46 \%$ mortality. The methanol WPE of $L$. carmeli and the aqueous FrE of $M$. azedarach (1:5) caused the highest mite mortality of $43.55 \%$ and $45.55 \%$, respectively and each was used as reference sample for potential acaricidal activity in the methanol and aqueous treatment groups. The latter extract was not significantly different in its effect from aqueous extracts of $M$. azedarach leaf extract (LE) and Achillea damascena WPE. Methanol extracts of Salvia rubifolia flowers and Calendula palestina FrE were found to be more active against the adult mite than their extracts of other plant parts as leaves and flowers, respectively. The former two extracts, flower extracts of Anthemis scariosa, Echinops gaillardoti, Nepeta curviflora, and Ranunculus cuneatus, leaves and stems extract of An. scariosa and WPEs of Melissa inodora, Ranunuculus myosuroides, Origanum libanoticum and Ac. damascena were found to be comparable in their acaricidal activity to that of the whole plant extract of $L$. carmeli. Thus, these bioactive extracts of some local plant species can cause toxicity to adult $T$. urticae mites and consequently could be an alternative control for mite pests.
\end{abstract}

Keywords: tetranychus, mite, plant extract, botanicals, medicinal, endemic

\section{Introduction}

The two spotted spider mite Tetranychus urticae Koch has been recorded from more than 900 different plant species and its polyphagous nature has been documented worldwide on at least 150 economical crops (Fasulo \& Denmark, 2009). Controlling mites by chemicals alone is particularly risky because of the ability of mites to become resistant to a wide range of pesticides especially when exposed to intensive selection pressures by the application of pesticides that encourage the evolution of acaricide resistance in T. urticae that consequently lead to outbreaks of T. urticae (Funayama, 2015). Resistance of T. urticae populations to organophosphates, carbamates, tetradifon, fenbutatin oxide and other acaricides is widely reported (Tsagkarakou et al., 2002; Khajehali et al., 2009). The degree of resistance to many established acaricides has resulted in a demand for new acaricides as plant derived materials with novel modes of action (Khater, 2012; George et al., 2014). Thus, these problems have established the need for alternative pest management control measures that include the search for new classes of pesticides and the reassessment and use of pest control agents of botanical origin. 
Many plants develop intrinsically secondary compounds as chemical defenses in their eco-habitat. These plants might be origin of biodegradable pesticides (Farombi, 2003). The world market for pesticides is large; it approximated $\$ 54.89$ billion in 2016 and projected to reach $\$ 70.57$ billion by 2021 , at a compound annual growth rate of 5.15\% from 2016 to 2021 (Anonymous, 2017) with the annual worldwide consumption of pesticides of about two million tons (De et al., 2014). However, there is increase in consumer demand for natural over synthetic pesticides nowadays. The structurally diverse natural compounds of bioactive plant extracts might exhibit against mite and insect pests various behavior responses as repellent, deterrent, antifeedant effects, and might exhibit physiological responses as growth regulator, molting inhibitor, reproduction inhibitor and toxic action. Many indigenous plants are known in the world as medicinal sources for treatment of various human diseases (Farombi, 2003). These plants might be used further locally as insecticides, acaricides, or rodenticides (Mishra et al., 2013).

Al-Alawi (2014) screened 18 plant extracts from the Mediterranean area for acaricidal activity against the mite $T$. urticae. Although all extracts were ineffective against the egg stage and caused less than $30 \%$ mortality; Al-Alawi (2014) indicated that the extracts of Ruta chalepensis L. and Astragalus oocephalus Boiss have the potential to be developed as botanical acaricide for T. urticae against both the deutonymph and adult instars. Erdogan et al. (2012) also determined the efficacy of 5 different plant extracts of Allium sativum L., Rhododendron luteum S., Helichrysum arenarium L., Veratrum album L., and Tanacetum parthenium L. against T. urticae. The highest mortality effect of the plant extracts against larvae and adult mite instars occurred at a concentration of $12 \%$ while the smallest effect was at $1 \%$.

Preserving the natural resources of endemic plants is one means for developing sustainable agro-ecosystems. It has been well established that certain plant-derived extracts and phytochemicals may provide potential alternatives to be used as pest control agents (Calmasur et al., 2006). The main objective of this study is to screen 29 medicinal plant species native to Lebanon for the bioactivity of their extracts against the adult T. urticae which has been reported to have resistance to pesticides in Lebanon; knowing that methanol extracts of these plant species, except Calendula palestina Pers. (Site 1) flowers and fruit extracts, were studied previously for their insecticidal effects against the cotton whitefly Bemisia tabaci (Gennadius) within a bioprospect context (Abou Fakhr et al., 2014), for utilizing local plant species as an alternative in pest management.

\section{Materials and Methods}

\subsection{Plant Extract Preparation}

Plant extraction was performed according to a methodology set for testing bioactivity of plant extracts at the Center of Initiative for Biodiversity Studies in Arid Regions-IBSAR (currently The Nature Conservation Center) located at the premises of the American University of Beirut (AUB), Lebanon.

\subsection{Plant Material}

Three hundred and eighteen plant genera indigenous to Lebanon with local medicinal and/or agricultural uses were investigated at IBSAR center. The initial plant list of 399 species was based on different bioactivity categories depending on the plant use by local people including pesticidal activity. Out of the latter list, 109 plants with acaricidal/insecticidal use have been recognized; this indicates that $27.3 \%$ of total plants revised for all above categories have pesticidal bioactivity, same as in previous study with B. tabcai (Abou Fakhr et al., 2014). In this study, the selected tested plant species were 30 plant species collected from different locations or sites (Tables 1 and 2). Plants in 11 botanical families were collected in Spring and Summer 2002 (between March and August) during which plants were collected for their fruits, flowers, leaves, or stems.

\subsection{Extraction of Plant Material}

Extraction of collected plant parts was executed at the Department of Chemistry, Faculty of Arts and Sciences, AUB. Harvested plant material was washed with distilled water and was dried at the laboratory at $25-32{ }^{\circ} \mathrm{C}$ with enough aeration for 2 weeks. Plants were separated physically into leaves, fruits, flowers and stems or used as a whole plant (stems, leaves and flowers combined), in case of low availability of the plant species. Then plant parts were ground into fine particles $(0.3 \mathrm{~mm}$ in diam.) by using a grinder (SM 100 Cutting Mill, Brinkman, Germany) at a speed of $1600 \mathrm{rpm}$ at $60 \mathrm{HZ}$.

The grinded plant material was soaked in methanol for $16 \mathrm{~h}$ and placed in a shaker-incubator at room temperature; as extraction of plant material at higher temperatures would denature or would change the chemical composition of the plant potential pesticidal bioactivity. The methanol solvent was used to extract most of the semi-polar and polar constituents. This $\mathrm{MeOH}$ extraction was performed using the standard plant material/solvent concentration of $1: 10(\mathrm{w}: \mathrm{v})$, this concentration was selected to avoid phytotoxicity by the 
unknown bioactivity of the tested plant extracts against the two-spotted spider mite. The extract was filtered by vacuum pressure (Buchi V-500, Switzerland) and filtrate of each raw extract was used in the bioassays. Forty two methanol extracts of 28 plant species were tested for their acaricidal bioactivity in this study (Table1).

Similar to the above procedure, 13 aqueous extracts of different plant parts of 8 plant species (Table 2) were prepared at a concentration of 1:5 (w:v); only Melia azedarach L. was tested against another concentration of (1:2) for leaf and fruit extracts (Table 2). These extracts were used in one bioassay as a preliminary test for a few medicinal plant species.

Table 1. List of 42 methanol extracts of 28 indigenous plant species tested for their acaricidal bioactivity against Tetranychus urticae adults

\begin{tabular}{|c|c|c|c|}
\hline Plant Family & Plant species & Plant part $/ \mathrm{s}^{\mathrm{a}}$ & Plant collection location $^{b}$ \\
\hline Apiaceae & Eryngium deserlorum Zohary & Whole plant & Zahle \\
\hline \multirow[t]{21}{*}{ Asteraceae } & \multirow[t]{2}{*}{ Achillea damascena L. (Loc. 1 and Loc. 2) } & Whole plant & Rassem El Hadath \\
\hline & & Whole plant & Hasroun \\
\hline & Anthemis hebronica Boiss. and Kotschy & Whole plant & Marjeyoun \\
\hline & \multirow[t]{2}{*}{ Anthemis scariosa Boiss. } & Flowers & \multirow[t]{2}{*}{ Marjeyoun } \\
\hline & & Leaves and stems & \\
\hline & \multirow[t]{3}{*}{ Calendula palestina Pers. (Loc.1) } & Leaves and stems & \multirow[t]{3}{*}{ Ibel El Saki (site1) } \\
\hline & & Flowers & \\
\hline & & Fruits & \\
\hline & \multirow[t]{3}{*}{ Calendula palestina Pers. (Loc. 2) } & Leaves and stems & \multirow[t]{3}{*}{ Ibel El Saki (site 2) } \\
\hline & & Flowers & \\
\hline & & Fruits & \\
\hline & Centaurea ainetensis Boiss. & Flowers & Aineta \\
\hline & Centaurea erengoides Lam. & Flowers & Jroud Hasroun \\
\hline & Cirsium sp. Boiss. & Whole plant & Bcharree \\
\hline & Echinops gaillardoti Boiss. & Flowers & Marjeyoun \\
\hline & Hieracium sp. L. & Whole plant & Kneisseh \\
\hline & Onopordum cynarocephalum Boiss. & Flowers & Sannine \\
\hline & \multirow[t]{2}{*}{ Serratula pusilla Dittr. (Loc. 1 and Loc. 2) } & Flowers & Mahmeit Baalabeck \\
\hline & & Flowers & Aineta \\
\hline & \multirow[t]{2}{*}{ Taraxacum sp. Poir. } & Leaves and stems & Nabee El Safa \\
\hline & & Flowers & Bcharree \\
\hline \multirow[t]{2}{*}{ Boraginaceae } & \multirow[t]{2}{*}{ Heliotropium rotundifolium Boiss. } & Leaves & Zahle \\
\hline & & Flowers & Sannine \\
\hline Dioscoreaceae & Tamus orientalis L. & Leaves and stems & Ibel El Saki \\
\hline Fabaceae & Lotus carmeli Boiss. & Whole plant & Chouf region \\
\hline \multirow[t]{9}{*}{ Lamiaceae } & Melissa inodora Bornm. & Whole plant & Nahr El Kaleb \\
\hline & \multirow[t]{3}{*}{ Nepeta curviflora Boiss. } & Flowers & \multirow[t]{3}{*}{ Deir El Kamar } \\
\hline & & Leaves & \\
\hline & & Stems & \\
\hline & Origanum libanoticum Boiss. & Whole plant & Nabee El Aassal \\
\hline & Phlomis damascena Born. & Whole plant & Mahmeit Baalabeck \\
\hline & Phlomis syriaca Boiss. & Whole plant & Mikne \\
\hline & \multirow[t]{2}{*}{ Salvia rubifolia Boiss. } & Leaves & \multirow[t]{2}{*}{ Barouk mountains } \\
\hline & & Flowers & \\
\hline \multirow[t]{2}{*}{ Ranunculaceae } & Ranunculus cuneatus Hook. & Flowers & Yanta \\
\hline & Ranunculus myosuroides Boiss. and Kotschy & Whole plant & Hasroun \\
\hline Rosaceae & Alchemilla diademata Rothm. & Whole plant & Aineta \\
\hline \multirow[t]{3}{*}{ Scrophulariaceae } & Verbascum blancheanum Boiss. & Leaves and stems & Rass Baalabeck \\
\hline & \multirow[t]{2}{*}{ Verbascum leptostychum DC. } & Leaves & Aineta \\
\hline & & Flowers & Nabee El Safa \\
\hline Urticaeceae & Urtica fragilis Thiebaut & Leaves and stems & Baskinta \\
\hline
\end{tabular}

Note. ${ }^{a}$ Whole plant includes leaves, flowers, and stems of the same plant ground together; ${ }^{b}$ Loc. $=$ Location. 
Table 2. List of 13 aqueous extracts of 8 indigenous plant species tested for their acaricidal bioactivity against Tetranychus urticae adults

\begin{tabular}{|c|c|c|c|}
\hline Plant Family & Plant species & Plant part $/ \mathbf{s}^{\mathrm{a}}$ & Plant collection location $^{b}$ \\
\hline \multirow[t]{3}{*}{ Asteraceae } & Achillea damascena $\mathrm{L}$. & Whole plant & Hasroun \\
\hline & Calendula officinalis L. & Flowers & Ibel El Saki \\
\hline & Serratula pusilla Dittr. & Whole plant & Aineta \\
\hline Lamiaceae & Phlomis damascena Born. & Leaves & Mahmeit Baalabeck \\
\hline \multirow[t]{2}{*}{ Ranunculaceae } & Ranunculus cuneatus Hook. & Flowers & Yanta \\
\hline & & Leaves & \\
\hline \multirow[t]{2}{*}{ Scrophulariacea } & Verbascum blancheanum Boiss. & Whole plant & Rass Baalabeck \\
\hline & & Leaves & \\
\hline Urticaeceae & Urtica fragilis Thiebaut & Leaves and stems & Baskinta \\
\hline \multirow[t]{4}{*}{ Meliaceae } & Melia azedarach L. & Leaves $(1: 5)$ & AUB campus \\
\hline & & Fruits (1:5) & \\
\hline & & Leaves $(1: 2)$ & \\
\hline & & Fruits $(1: 2)$ & \\
\hline
\end{tabular}

Note. ${ }^{\mathrm{a}}$ Whole plant includes leaves, flowers, and stems of the same plant ground together; ${ }^{\mathrm{b}} \mathrm{AUB}=\mathrm{American}$ University of Beirut.

\subsection{Screening Bioassays with Plant Extracts against T. urticae}

All experiments were performed at the Entomology Laboratory, Faculty of Agricultural and Food Sciences, AUB at $25 \pm 2{ }^{\circ} \mathrm{C}, 60 \pm 10 \% \mathrm{RH}$ and 16:8 (L:D) photoperiod. Treatments included 55 extracts of 30 plant species with 1 negative control: Methanol $(10 \%)$ or distilled water in case of aqueous extracts. Each treatment was replicated 3 times on one date of the experiment. The experiment was replicated at 3 different dates during the study. Due to the availability of consistent conditions during the experiments with adult mites; about 15 treatments were performed simultaneously on different days of the experiment allowing about 45 Petri dishes to be assessed at one date.

\subsubsection{Mite Colony}

T. urticae colony was raised in a glasshouse compartment under controlled conditions of $28 \pm 5{ }^{\circ} \mathrm{C}, 80 \pm 10 \% \mathrm{R} . \mathrm{H}$. and a photoperiod of 14:10 (L:D). The colony, originally from a field population (previously exposed to pesticides) was reared on cucumber plants of the variety Perla (Edena Seeds, USA) in a mite proof cage (140 $\times$ $85 \times 130 \mathrm{~cm})$ covered completely with mesh $(270 \times 770 \mu \mathrm{m})$. Two true leaf seedlings were grown to provide a source of healthy plants to the mite colony and bioassays. Irrigation and fertilization with Floral ${ }^{\circledR}(20-20-20+$ microelements; Cifo S.p.A., Bologna, Italy) was applied about 2 times a week, as needed.

\subsubsection{Experimental Setup with Adult mites}

Non-infested soft cucumber leaves of $4 \mathrm{~d}$ old were detached from the tip of plants to be used in the bioassays. Each leaf was placed in a glass dish $(12.5 \mathrm{~cm}$ diam. $\times 5 \mathrm{~cm}$ depth); the petiole of the leaf was inserted in a narrow necked small vial filled with water to prolong the rigidity of the leaf throughout the experiment.

Five $\mathrm{ml}$ of each methanol extract was rotovaped (Centrivap console, Labconco, USA), after which $5 \mathrm{ml}$ of distilled water was added and mixed with a vortex (Vortex V1 plus, Boeco, Germany) to homogenize the solution before spraying the mites on the leaf surface. Leaves and mites were sprayed topically by methanol or aqueous extract; each leaf received an average of $2.5 \mathrm{ml}$ of the extract or the control (10\% Methanol or distilled water) using $10 \mathrm{ml}$ glass sprayers.

Adult female mites recognized by their elliptical body and non-tapering caudal end and 12 pairs of dorsal setae (Fasulo \& Denmark, 2009) were collected from the rearing colony and introduced into each glass dish and placed over the leaf before treatment; each dish was sealed with parafilm after treatment. Each treatment was replicated 9 times. Each replicate comprised 10 adult female mites per cucumber leaf. Numbers of adult mites dead or alive in each dish were recorded at $48 \mathrm{~h}$ after treatment; this selected timing was the best based on the healthy status of the leaves. Assessment of mite mortality corresponded to failure of mite response to probing with a thin needle: with no movements of legs, proboscis, or abdomen. 


\subsubsection{Statistical Analysis}

The experiments were laid out in a completely randomized block design with two factors: treatment and date of experiment. Each treatment was replicated 9 times on 3 different dates. Data was analyzed by the statistical package MSTAT (Anonymous, 1991). The data were pooled and analyzed as a one-way ANOVA with treatment as the main factor, as there was no significant interaction among the 2 factors. Thus, there were 42 treatments with methanol extracts and 1 negative control (Methanol 10\%) with 9 replicates per treatment. On the other hand, there were 13 treatments with aqueous extracts and 1 negative control (distilled water) with 9 replicates per treatment. The $\%$ mortality of adult mites per leaf were used in the data analysis, after ensuring their normal distribution by transforming the data using Arcsin Sqrt. (\% x), with $x$ being the adjusted $\%$ mortality, to stabilize the variances. The adjusted \% mortality is the mortality data corrected according to the control mortality using Abbott's (1925) formula as the mites mortality in the control of the experiments was of an average of 5\%. All means were separated by LSD test, if significant $F$ values were obtained.

\section{Results}

This study is the first report for the potential effect/s on survival of $T$. urticae for the tested indigenous medicinal plant species (Tables 1 and 2), except for Phlomis syriaca Boiss. and M. azedarach that were studied previously against T. urticae (Al-Alawi, 2014; Ashrafju et al., 2014, respectively). Results of our current study have shown efficacy in decreasing number of live adult mites in some treatments with plant extracts of these medicinal plants, under laboratory conditions.

\subsection{Effect of Organic Plant Extracts}

In our bioassays with methanol extracts, there were significant differences in \% mortality of the adult mites among treatments. The 42 methanol extract treatments were divided into seven groups for discussion simplification of the results. The first major treatment groups included: 13 whole plant extracts (WPEs), 15 flower extracts (FEs), 7 leaf and stem extracts (LSEs) and 4 leaf extracts (LEs). The $5^{\text {th }}$ treatment group including the 3 remaining extracts, 2 fruit extracts and one stem extract, are discussed in a comparative manner related to different plant parts of the same plant species collected from one location; the latter group included 13 extracts of Sa. rubifolia, An. scariosa, N. curviflora and Ca. palestina (plant parts collected from 2 locations). The $6^{\text {th }}$ treatment group dealt with effect of plant source (collection location/site) on bioactivity of the extracts. This group included 10 extracts related to Ac. damascena, Ca. palestina and Se. pusilla, each sp. collected from 2 locations/sites (Table 1). The $7^{\text {th }}$ treatment group dealt with effect of similar plant parts of different species within one plant genus on bioactivity of the extracts; this group included 4 extracts of $P$. damascena, $P$. syriaca, Ce. erengoides and Ce. ainetensis.

For the whole plant extracts (WPEs), there was significant difference in \% mite mortality among treatments. The WPE of $L$. carmeli showed the highest mortality of $43.55 \%$ among all treatments and hence it is used as the reference sample for high acaricidal activity in methanol extracts treatment groups. Whole plant extracts of $\mathrm{Al}$. diademata, Er. deserlorum, Melis. inodora, R. myosuroides, Or. libanoticum, and Ac. damascena caused 42.96, $41.23,36.92,35.09,31.80$ and $31.48 \%$ mortality, respectively and were not significantly different in their effect from that of $L$. carmeli (Table 3). However, the other 6 WPEs were significantly lower in their effect from $L$. carmeli with P. damascena causing the lowest mite mortality of $18.41 \%$.

For the flower extracts (FEs), there was significant difference in \% mortality of adult mites among treatments with 15 FEs of different plant species (including two plant species, Se. pusilla and Ca. palestina, collected from 2 locations, Table 1). Flower extracts of Sa. rubifolia, An. scariosa, Ec. gaillardoti, N. curviflora and R. cuneatus caused high mortality of $38.48,33.57,32.83,31.41$ and $29.95 \%$, respectively and were not significantly different in their effect from that of the WPE of $L$. carmeli (Table 3). However, the other 10 FEs were significantly lower in their effect from L. carmeli with Ca. palestina causing the lowest mite mortality of $15.63 \%$.

For the leaf and stem extracts (LSEs), there was significant difference in \% mortality of adult mites among treatments with 7 LSEs of different plant species. Only LSE of An. scariosa was not significantly different in its effect from L. carmeli causing a mortality of $34.33 \%$. On the contrary, the other 6 LSEs were significantly lower in their effect from $L$. carmeli with $V$. blancheanum causing the lowest mite mortality of $17.75 \%$ (Table 3). However, the latter LSEs were not significantly different in their effect from that of An. scariosa.

For the leaf extracts (LEs), there was significant difference in \% mortality of adult mites among 4 LEs of different plant species and L. carmeli. Leaf extracts of N. curviflora, He. rotundifolium, V. leptostychum, and Sa. rubifolia caused significantly low acaricidal effect in the range of $15.26 \%-25.20 \%$ mite mortality in comparison to WPE of L. carmeli (Table 3). 
In comparing extracts of different plant parts of one plant sp. collected from same location, there was significant difference in \% mite mortality (Table 3) among 13 treatments with extracts of different parts of each of the following plant species: Sa. rubifolia, An. scariosa, N. curviflora and Ca. plaestina. There was a significant difference in mite mortality between the FE and LE of Sa. rubifloia, but there was no significant difference in \% mite mortality between the LSE and the FE of An. scariosa. Similarly, for the 3 extracts of $N$. curviflora, there was no significant difference in \% mite mortality among extracts of different plant parts: leaves, stems and flowers. On the other hand, the fruit extract (FrE) and FE of Ca. palestina from one location (labeled as location 2 , Table 1) was significantly different in $\%$ mite mortality from that of its LSE. On the contrary, there was no significant difference among the FrE, LSE and FE of Ca. palestina collected from another location (labeled as location 1, Table 1); all 3 extracts were not comparable in their effect to that of L. carmeli WPE (Table 3). However, the FEs of Sa. rubifolia, An. scariosa and N. curviflora and LSE of An. scariosa and FrE of Ca. palestina seem to be comparable in their acaricidal effects to WPE of L. carmeli.

In comparing extracts of similar plant parts of a plant species collected from different locations/sites, there was no significant difference in \% mite mortality among 10 treatments with extracts of similar plant parts of three plant species; each species collected from 2 locations/sites. The WPEs of Ac. damascena, FEs of Se. pusilla, FEs, LSEs and FrEs of Ca. palestina collected from different locations were not significantly different in their effect against the mites (Table 3).

In comparing treatments with extracts of same plant part of four species within 2 plant genera: Centaurea and Phlomis, there was no significant difference in \% mite mortality among these extracts. Difference in bioactivity effect of species within plant genus is not reflected in this study for the tested plant extracts of Centaurea sp. and Phlomis sp. Furthermore, FEs of Ce. erengoides and Ce. ainetensis and WPEs of P. syriaca and P. damascena were significantly lower in \% mite mortality from that of WPE of $L$. carmeli and caused low mite mortality of $18.41 \%-28.26 \%$ (Table 3).

\subsection{Effect of Aqueous Plant Extracts}

In our bioassays with 13 aqueous plant extracts, there were significant differences in \% mite mortality among treatments (Table 4). M. azedarach $\mathrm{FrE} \mathrm{(1:5)} \mathrm{had} \mathrm{shown} \mathrm{the} \mathrm{highest} \mathrm{mite} \mathrm{mortality} \mathrm{of} 45.55 \%$ and hence it is used in comparison with other aqueous extracts as reference sample for high acaricidal activity. The latter extract was not significantly different in its effect from M. azedarach LE (1:5) and Ac. damascena WPE causing mite mortality of 35.55 and $26.6 \%$, respectively. However, the other 10 extracts were significantly lower in their effect from the reference M. azedarach FrE (1:5). 
Table 3. Mortality of T. urticae adult mites caused by methanol extracts of different plant species under laboratory conditions

\begin{tabular}{|c|c|c|}
\hline Treatment $^{\mathrm{a}}$ & Plant part $/ \mathbf{s}^{\mathrm{b}}$ & $\%$ mortality $^{\mathrm{c}}$ \\
\hline Lotus carmeli & Whole plant & $43.55 \pm 8.40 \mathrm{a}$ \\
\hline Alchemilla diademata & Whole plant & $42.96 \pm 10.73 \mathrm{ab}$ \\
\hline Eryngium deserlorum & Whole plant & $41.23 \pm 8.65 \mathrm{abc}$ \\
\hline Salvia rubifolia & Flowers & $38.48 \pm 3.45 \mathrm{a}-\mathrm{d}$ \\
\hline Melissa inodora & Whole plant & $36.92 \pm 4.49$ a-e \\
\hline Ranunculus myosuroides & Whole plant & $35.09 \pm 7.11 \mathrm{a}-\mathrm{f}$ \\
\hline Anthemis scariosa & Leaves and stems & $34.33 \pm 9.14 \mathrm{a}-\mathrm{f}$ \\
\hline Anthemis scariosa & Flowers & $33.57 \pm 8.42 \mathrm{a}-\mathrm{g}$ \\
\hline Echinops gaillardoti & Flowers & $32.83 \pm 1.68 \mathrm{a}-\mathrm{h}$ \\
\hline Origanum libanoticum & Whole plant & $31.80 \pm 6.35 \mathrm{a}-\mathrm{i}$ \\
\hline Achillea damascena (Loc.1) & Whole plant & $31.48 \pm 9.23 \mathrm{a}-\mathrm{i}$ \\
\hline Nepeta curviflora & Flowers & $31.41 \pm 7.85 \mathrm{a}-\mathrm{i}$ \\
\hline Calendula palestina (Loc. 2) & Fruits & $30.52 \pm 5.24 \mathrm{a}-\mathrm{j}$ \\
\hline Ranunculus cuneatus & Flowers & $29.95 \pm 6.81 \mathrm{a}-\mathrm{k}$ \\
\hline Serratula pusilla (Loc. 2) & Flowers & $28.81 \pm 7.85 \mathrm{~b}-1$ \\
\hline Nepeta curviflora & Stem & $28.46 \pm 6.97 \mathrm{~b}-1$ \\
\hline Tamus orientalis & Leaves and stems & $28.32 \pm 5.19 \mathrm{c}-1$ \\
\hline Centaurea erengoides & Flowers & $28.26 \pm 4.67 \mathrm{c}-1$ \\
\hline Verbascum leptostychum & Flowers & $27.77 \pm 8.33 \mathrm{c}-1$ \\
\hline Achillea damascena (Loc. 2) & Whole plant & $26.72 \pm 6.45 \mathrm{c}-1$ \\
\hline Serratula pusilla (Loc. 1) & Flowers & $26.58 \pm 7.12 \mathrm{~d}-1$ \\
\hline Taraxacum sp. & Leaves and stems & $26.29 \pm 6.53 \mathrm{~d}-1$ \\
\hline Anthemis hebronica & Whole plant & $25.77 \pm 5.80 \mathrm{~d}-1$ \\
\hline Nepeta curviflora & Leaves & $25.20 \pm 5.46 \mathrm{~d}-1$ \\
\hline Centaurea ainetensis & Flowers & $24.97 \pm 4.61 \mathrm{~d}-1$ \\
\hline Heliotropium rotundifolium & Leaves & $24.75 \pm 6.50 \mathrm{~d}-1$ \\
\hline Calendula palestina (Loc. 1) & Fruits & $23.49 \pm 4.59$ e- 1 \\
\hline Urtica fragilis & Leaves and stems & $23.23 \pm 7.60 \mathrm{e}-1$ \\
\hline Phlomis syriaca & Whole plant & $22.64 \pm 4.55 \mathrm{e}-1$ \\
\hline Calendula palestina (Loc. 1) & Leaves and stems & $21.79 \pm 2.90 \mathrm{f}-1$ \\
\hline Heliotropium rotundifolium & Flowers & $20.54 \pm 7.54 \mathrm{f}-1$ \\
\hline Calendula palestina (Loc. 2) & Flowers & $19.59 \pm 5.53 \mathrm{~g}-1$ \\
\hline Hieracium $\mathrm{sp}$. & Whole plant & $18.96 \pm 5.57 \mathrm{~h}-1$ \\
\hline Cirsium sp. & Whole plant & $18.48 \pm 3.71 \mathrm{~h}-1$ \\
\hline Phlomis damascena & Whole plant & $18.41 \pm 2.95 \mathrm{~h}-1$ \\
\hline Taraxacum sp. & Flowers & $18.18 \pm 5.97 \mathrm{I}-1$ \\
\hline Calendula palestina (Loc. 2) & Leaves and stems & $18.05 \pm 7.54 \mathrm{f}$ \\
\hline Verbascum blancheanum & Leaves and stems & $17.75 \pm 7.54 \mathrm{f}$ \\
\hline Onopordum cynarocephalum & Flowers & $16.75 \pm 4.06 \mathrm{j}-1$ \\
\hline Calendula palestina (Loc. 1) & Flowers & $15.63 \pm 3.17 \mathrm{k}-1$ \\
\hline Verbascum leptostychum & Leaves & $15.43 \pm 2.17 \mathrm{k}-1$ \\
\hline Salvia rubifolia & Leaves & $15.26 \pm 4.651$ \\
\hline
\end{tabular}

Note. Values $=$ Mean \pm Std. Error; ${ }^{\mathrm{a}}$ Loc. $=$ Location; ${ }^{\mathrm{b}}$ Whole plant includes leaves, flowers, and stems of the same plant ground together; ${ }^{\mathrm{c}}$ Means followed by the same letter within a column are not significantly different (LSD test; $\mathrm{P}>0.05)$. 
Table 4. Mortality of T. urticae adult mites caused by aqueous extracts of different plant species under laboratory conditions

\begin{tabular}{lll}
\hline Treatment & Plant part/s $^{\mathrm{a}}$ & $\mathbf{\% ~ m o r t a l i t y ~}^{\mathrm{b}}$ \\
\hline Melia azedarach $(1: 5)$ & Fruits & $45.55 \pm 5.3 \mathrm{a}$ \\
Melia azedarach $(1: 5)$ & Leaves & $35.55 \pm 6.48 \mathrm{ab}$ \\
Achillea damascena & Whole plant & $26.66 \pm 8.82 \mathrm{abc}$ \\
Melia azedarach $(1: 2)$ & Leaves & $18.88 \pm 6.55 \mathrm{bc}$ \\
Verbascum blancheanum & Leaves and stems & $18.88 \pm 6.55 \mathrm{bc}$ \\
Phlomis damascena & Whole plant & $15.55 \pm 5.55 \mathrm{bc}$ \\
Calendula officinalis & Flowers & $13.33 \pm 3.72 \mathrm{bc}$ \\
Melia azedarach $(1: 2)$ & Fruits & $12.22 \pm 3.64 \mathrm{bc}$ \\
Serratula pusilla & Flowers & $11.11 \pm 3.09 \mathrm{bc}$ \\
Urtica fragilis & Leaves and stems & $11.11 \pm 3.89 \mathrm{c}$ \\
Verbascum blancheanum & Whole plant & $8.88 \pm 3.89 \mathrm{c}$ \\
Ranunculus cuneatus & Leaves & $6.66 \pm 2.88 \mathrm{c}$ \\
Ranunculus cuneatus & Flowers & $6.66 \pm 2.88 \mathrm{c}$ \\
\hline
\end{tabular}

Note. Values $=$ Mean \pm Std. Error; ${ }^{a}$ Whole plant includes leaves, flowers, and stems of the same plant ground together; ${ }^{b}$ Means followed by the same letter within a column are not significantly different (LSD test; P > $0.05)$.

\section{Discussion}

In general, the bioactivity effect of the plant extracts against arthropods as mites might be related to the extracted plant part, the plant species, the source (i.e. collection location/site) of the plant material and the mite instar. A few studies have reported various effects on mites by a number of other plant species belonging to the same genera of the medicinal plant species that were tested in this study. Our treatments with methanol or aqueous extracts of some medicinal plants applied topically over adult mites infesting cucumber leaves caused a relative high toxic effect against mites depending on the extracted plant part/s and biochemical characteristics of the plant species. In comparing the bioactivity of methanol extracts of the four major plant parts, 53.84\% of the WPEs, $33.33 \%$ of the FEs and $14.28 \%$ of the LSEs were having acaricidal activity above $29.95 \%$. Similarly, the fruit extract of $\mathrm{Ca}$. Palestina has comparable acaricidal effect to the aforementioned extracts. However, all tested LEs, methanol and aqueous LSEs of $U$. fragilis caused lower mortality of mites less than 26\% (Table 3 ). Similarly, Al-Alawi (2014) found that the extract of Urtica pilulifera L. did not influence young adult female mites of T. urticae, but it caused high deutonymph mortality of $51 \%$.

In our study, methanol WPEs of L. carmeli, Al. diademata, R. myosuroides and Ac. damascena were found to have potential acaricidal effect under laboratory conditions. Both L carmeli and Al. diademata WPEs were previously reported to have a repellent effect against adult B. tabaci, but WPEs of $R$. myosuroides and Ac. damascena caused both repellent and toxic effects against adult and $2^{\text {nd }}$ nymphal instars of $B$. tabaci, respectively (Abou Fakhr Hammad et al., 2014). Thus, these WPEs seem to have acaricidal toxic effect in addition to their latter determined insecticidal effects. However, WPEs of Phlomis sp. were also found to have repellent effect against $B$. tabaci, but caused low acaricidal activity in our study (Table 3 ). The acaricidal effect of our former plant extracts (Table 3) seems to be similar to that of other synthetic chemical acaricides as Hexythiazox that caused $17-30.83 \%$ T. urticae mortality in treated plots compared to other acaricides as Fenpyroximate, Spiromecifen and Pyridaben that caused 82-95\% mite mortality; the lower effect of Hexythiazox was also reported under laboratory conditions (Ali et al., 2015).

On the other hand, L. carmeli belongs to the Family Fabaceae/Leguminosae which frequently contains alkaloids; phytochemical analysis of Lotus spp. also included coumarins, flavonoids and tannins with potential antimicrobial activity (Girardi et al., 2014). Similarly, Alchemilla species (Rosaceae) were found to have tannins and catechins, phytochemical profile of various Ranunculus species (Ranunculaceae) included different secondary metabolite groups as triterpene saponins, alkaloids, cyanogenic glucosides that might be related to antioxidant and antibacterial activities (Wink, 2015). It is important to note that the 3 main chemical classes in plant species that were known for insecticidal, fungicidal and other biological activities were terpenoids, phenylpropanoids and alkaloids as in Heliotropium sp. (Boraginaceae), Tamus sp. (Dioscoreaceae), Verbascum sp. (Scrophulariaceae), Urtica sp. (Urticaceaea), Lamiaceae (as Phlomis \& Origanum spp.), Apiaceae and 
Achillea species (Asteraceae) which are also known to have polyacetylenes or polyenes, phenolic acids, coumarins, and sterols which are usually related to their medical effects (Wink, 2015).

Flower extracts of Sa. rubifolia, An. scariosa, Ec. gaillardoti, N. curviflora and R. cuneatus were also found to have potential toxic acaricidal effect. However, only Ec. gaillardoti FE caused significant decrease in number of whitefly live nymphs on treated plants which indicates that this extract seems to have both acaricidal and insecticidal effects, but FEs of Se. pusilla and On. cynarocephalum which were found to have an insecticidal effect against the whitefly (Abou Fakhr et al., 2014) were not found to have a significant acaricidal effect in our current study (Table 3).

Only An. scariosa LSE seems to have potential toxic acaricidal effect among the 7 tested LSEs. The former extract seems to have both acaricidal and insecticidal effects against $B$. tabaci, but LSEs of Ca. palestina, $T$. orientalis and $V$. blancheanum and LEs of $N$. curviflora, He. rotundifolium, V. leptostychum, and Sa. rubifolia which were found to have significant insecticidal effects against B. tabaci (Abou Fakhr et al., 2014) were found to have low acaricidal effect in our current study.

In comparing bioactivity of extracts of different plant parts of one plant sp. collected from same location in terms of acaricidal activity against $T$. urticae (our current study) and insecticidal effect against B. tabaci (Abou Fakhr Hammad et al., 2014), Salvia rubifloia FE, LE and FrE, LSE of Ca. palestina have acaricidal and insecticidal effects, respectively in each plant species; whereas, LSE of An. scariosa seem to have both acaricidal and insecticidal effects, but its FE has only acaricidal effect which is similar to that of $N$. curviflora FE. Thus, the secondary metabolites vary depending on part of the plant studied as flower, leaf, stem or fruit. Furthermore, methanol LEs and FrEs of M. azedarach tree were found to be repellent to whitefly adults, while the fruit extracts have caused a significant detrimental effect against nymphs of B. tabcai (Jazzar \& Abou-Fakhr Hammad, 2003) and Bemisia argentifolii (Bellows \& Perring) (Abou-Fakhr Hammad \& McAuslane, 2006). Furthermore, the secondary plant metabolites may vary due to several factors besides the plant part studied; as the degree of plant maturity at the collection period of the sample and other factors as geography of the collection location/site.

In our study, there was no location effect on the bioactivity of the plant part extract of one species collected from different locations/sites against the mite T. urticae. However, the WPE of Ac. damascena (collected from labeled location 1, Table 1) and fruit extract of Ca. palestina (collected from labeled location 2) seems to have potential acaricidal effects. Similarly, there was no location effect on the extracts bioactivity of the plant sp. Ca. palestina, Se. pusilla and Ac. damascena against the insect pest B. tabaci (Abou Fakhr Hammad et al., 2014). However, WPE of Ac. damascena (collected from labeled location1) have both acaricidal and insecticidal effects, but the FrE of Ca. palestina (collected from labeled location 2) have only acaricidal effect. This "no location" effect could be attributed to the fact that the two collection locations/sites for particular species are geographically not widely distant from each other. For example, plant samples of $C a$. palestina LSEs were collected from 2 sites in one location, Ibel El Saki; plant samples of Se. pusilla FEs were collected from 2 locations in Baalbek District; plant samples of Ac. damascena WPEs were collected from two locations in close districts (Table 1). However, certain studies have confirmed that some plant species have distinct chemotypes or populations that are often separated geographically (Pascual-Villalobos \& Ballesta-Acosta, 2003). Thus, the location or site factor is associated to a phenomenon which relates the variability in production of a secondary plant compound to strong biogeographic dependence; for example, it was reported that crude extracts of M. azedarach from Paraguay were devoid of any anti-molting activity whereas this activity was found in the Brazilian M. azedarach (Cabral et al., 1996).

Furthermore, difference in bioactivity effect of species within plant genus is not reflected in this study for the tested methanol plant extracts. The FEs of Ce. erengoides and Ce. ainetensis and WPEs of $P$. syriaca and $P$. damascena, caused low acaricidal effect against the mite T. urticae. Similarly, this bioactivity effect was not reflected for the plant extracts of the genera: Centaurea and Phlomis against B. tabaci (Abou Fakhr Hammad et al., 2014), but these extracts caused high insecticidal effects against the whitefly.

For the treatments with our aqueous extracts against the mite $T$. urticae, FrE and LE of M. azedarach (1:5) caused the highest mite mortality of $45.55 \%$ and $35.55 \%$, respectively (Table 4). However, Ashrafju et al. (2014) found that $M$. azedarach extract concentrations of 4 and $5 \mathrm{mg} / \mathrm{ml}$ caused a reduction of more than $50 \%$ in the egg laying of T. urticae mites and a significant increase in their pre-mature period. These latter extracts proved to be more efficacious as the volume of water used was larger than that of the FrE and LE of M. azedarach (1:2), leading to extracting more of the bioactive material; this is similar to Neem, a related meliaceous tree, which is known to be of very low solubility in water which urges the need for a larger amount of water to be used for 
extracting the bioactive constituents (Anonymous, 1992). Furthermore, all extracts in our study were tested as raw extracts without the addition of any surfactant; the aqueous WPE of $P$. damascena caused only $15.55 \%$ mite mortality whereas, Al-Alawi (2014) found that aqueous LEs of $P$. syriaca with Tween-80 caused mortality of 65\%, followed by Achillea biebersteinii Afan. (64\%) against the adult T. urticae.

In comparing the bioactivity of our plant extracts in different solvents, the aqueous and methanol WPEs (collected from labeled locations 2 and 1) of Ac. damascena caused comparable mite mortality of 26.66, 26.72 and $31.48 \%$, respectively. Similarly, the aqueous and methanol LSE of $V$. blancheanum caused a comparable mite mortality of $18.88 \%$ and $17.75 \%$, respectively. However, other aqueous extracts had caused in general a lower mite mortality of 6.66 till $15.55 \%$ (Table 4) compared to their corresponding methanol extracts (Table 3). Furthermore, $M$. azedarach methanol extracts were found to be more active against $B$. tabaci than extracts with other solvents as acetone, ether and water (Abou-Fakhr Hammad et al., 2000). On the other hand, neem methanol extracts were reported to be 50 times more concentrated than water extracts that were effective as pesticides (Anonymous, 1992). Govindachari et al. (1999) also found that water extracts of neem seeds contain all the principal triterpenoids but much less than subsequent extraction with methanol.

In general, raw plant products are not highly water-soluble for extraction of the active ingredients which makes them difficult for application, but these products are convenient for farmers, as they do not involve any costly solvents. Although, extraction with water is the most effective for bulk application of plant extracts, one limitation is the level of stability of secondary compounds in the plant extracts. Furmanowa et al. (2002) found that aqueous extracts of Taxus cuspidata Siebold \& Zucc. stems and leaves have strong antifeedant activity against mites, but hot water extraction of this plant lowered the reproductive rate of $T$. urticae from 70.24 in the control to $6.70 \%$. They also indicated that aqueous extracts of Taxus baccata var. elegantissima had a significant effect on mortality, development and fecundity of T. urticae. Thus, the extraction method may affect the constituents of the extract and consequently its bioactive properties.

Therefore, for transferring laboratory results to the field application, besides the continuous search needed for suitable organic solvents to extract pesticidal secondary plant compounds, other factors are also needed. Plant extracts might also have low residual stability on plants especially that it is known that pesticides of botanical origin are susceptible to UV degradation. For example, Azadirachtin (Azamax ${ }^{\circledR} 12 \mathrm{~g} / \mathrm{L}$ ) was efficient against $T$. urticae, with a mortality rate similar to that of abamectin, but with less persistence level of 7 days versus 21 days for abamectin (Bernardi et al., 2013). Thus, increasing the persistence level of the botanical insecticidal extract on the plant is needed to increase the pesticide effect and to enhance the application of botanical products. The activity of neem based formulations on mites as solvents and additives in neem seed kernel extracts were reported to influence the mortality, repellency, and fecundity of mites; the two commercial preparations of neem seed kernels Margosan-O and Neem azal-S with $3000 \mathrm{ppm}$ and $3500 \mathrm{ppm}$ azadirachtin, respectively were effective in decreasing the population of T. urticae (Dimetry et al., 1993).

Finally, we conclude that 14 extracts out of 42 methanol extracts and 3 extracts out of 13 aqueous extracts of endemic medicinal plants were found to have a potential high bioactivity against $T$. urticae adults. The effect of these bioactive extracts would be enhanced by selecting other organic solvents for extraction or by increasing the concentration of the active ingredient of these extracts, pending there will be no phytotoxicity to the tested plants. Furthermore, the most bioactive extracts as L. carmeli (WPE) and M. azedarach fruit and leaf extracts need to be further investigated against the immature instars of the mite, with more concentrated aqueous or other organic solvent extracts and/or in combination with other additives that would enhance the bioactivity against different stages of the mites at the laboratory and under field conditions.

\section{References}

Abbott, S. (1925). A method of computing the effectiveness of an insecticide. J. Econ. Entomol., 18, 264-267. https://doi.org/10.1093/jee/18.2.265a

Abou Fakhr Hammad, E., Zeaiter, A. W., Saliba, N., \& Talhouk, S. (2014). Bioactivity of indigenous medicinal plants against the cotton whitefly, Bemisia tabaci. J. Insect Sci., 14, Article 105, 1-18. https://doi.org/ 10.1673/031.014.105

Abou-Fakhr Hammad, E. M., Nemer, N. M., Hawi, Z. K., \& Hanna, L. T. (2000). Responses of the sweetpotato whitefly, Bemisia tabaci, to the Chinaberry tree (Melia azedarach L.) and its extracts. Annals of Applied Biology, 137, 79-88. https://doi.org/10.1111/j.1744-7348.2000.tb00039.x

Abou-Fakhr Hammad, E., \& McAuslane, H. (2006). Effect of Melia azedarach L. Extract on Bemisia argentifolii (Homoptera: Aleyrodidae) and its Biocontrol Agent Eretmocerus rui (Hymenoptera: 
Aphelinidae). Environ. Entomol., 35(3), 740-745. Retrieved from http://www.bioone.org/doi/abs/10.1603/ 0046-225X-35.3.740

Al-Alawi, M. S. (2014). Acaricidal Activity of Medicinal Plants against the Developmental Stages of the Two Spotted Spider Mite, Tetranychus urticae (Acari: Tetranychidae). Inter. J. Agric. Res., 9(1), 38-46. https://doi.org/10.3923/ijar.2014.38.46

Ali, A., Khan, I. A., Maula, F., \& Yasmin, B. (2015). Comparative efficacy of acaricides against two spotted spider mites, Tetranychus urticae Koch (Acari: Tetranychidae) on kidney bean plants under laboratory and field conditions. International Journal of Technical Research and Applications, 3(6), 170-175.

Anonymous. (1991). User's guide to MSTAT-C. East Lansing, Michigan, USA: Michigan State University.

Anonymous. (1992). Neem: A tree for solving global problems (p. 141). National Research Council, Washington DC: National Academy Press.

Anonymous. (2017). Crop Protection Chemicals Market by Type (Herbicides, Insecticides, and Fungicides), Origin (Synthetic, and Biopesticides), Crop Type (Cereals \& Oilseeds, Fruits \& Vegetables), Mode of Application, Form, and by Region. Global Forecasts to 2021. Markets and Markets Research Private Ltd.

Ashrafju, M., Ahmadi, K., \& Hamidi, H. (2014). Different concentrations of Melia azedarach L. (Meliaceae) ethanolic extract on the developmental time and egg laying of Tetranychus urticae Koch. Archives of Phytopathology and Plant Protection, 47(18), 2242-2247. https://doi.org/10.1080/03235408.2013.871791

Bernardi, D., Botton, M., Silva da Cunha, U., Bernardi, O., Malausa, T., Garciac, M. S., \& Navae, D. E. (2013). Effects of azadirachtin on Tetranychus urticae (Acari: Tetranychidae) and its compatibility with predatory mites (Acari: Phytoseiidae) on strawberry. Pest Manag. Sci., 69, 75-80. https://doi.org/10.1002/ps.3364

Cabral, M. M. O., Rembold, E. S. G. H., Simone, S. G. D., \& Kalecom, A. (1996). Anti-moulting activity in Brazilian Melia azedarach. Mem. Inst. Oswaldo Cruz., 91, 117-118. https://doi.org/10.1590/S0074-02761 996000100021

Calmasur, O., Aslan, I., \& Sahin, F. (2006). Insecticidal and acaricidal effect of three Lamiaceae plant essential oils against Tetranychus urticae Koch and Bemisia tabaci Genn. Industrial Crops and Products, 23, 140-146. https://doi.org/10.1016/j.indcrop.2005.05.003

De, A., Bose, R., Kumar, A., \& Mozumdar, S. (2014). Targeted Delivery of Pesticides Using Biodegradable Polymeric Nanoparticles. SpringerBriefs in Molecular Science (pp. 5-6). https://oi.org/10.1007/ 978-81-322-1689-6_2

Dimetry, N. Z., Amer, S. A. A., \& Reda, A. S. (1993). Biological activity of two neem seed kernel extracts against the two-spotted spider mite Tetranychus urticae Koch. J. Appl. Entomol., 116, 308-312. https://doi.org/10.1111/j.1439-0418.1993.tb01201.x

Erdogan, P., Yildirim, A., \& Sever, B. (2012). Investigations on the Effects of Five Different Plant Extracts on the Two-Spotted Mite Tetranychus urticae Koch (Arachnida: Tetranychidae). Psyche., 5, Article ID: 125284. https://doi.org/10.1155/2012/125284

Farombi, E. O. (2003). African indigenous plants with chemotherapeutic potentials and biotechnological approach to the production of bioactive prophylactic agents. Afr. J. Biotechnol., 2(12), 662-671. https://doi.org/10.5897/AJB2003.000-1122

Fasulo, T. R., \& Denmark, H. A. (2009). Featured Creatures. Two-spotted Spider Mite, Tetranychus urticae Koch. (Arachnida: Acari: Tetranychidae). Entomology and Nematology Department Publication No. EENY-150. Florida Cooperative Extension Service, Institute of Food and Agricultural Sciences, University of Florida.

Funayama, K. (2015). Outbreaks of the two-spotted spider mite, Tetranychus urticae (Acari: Tetranychidae) are caused by broad-spectrum insecticide spraying in apple orchards. Appl. Entomol. Zool., 50, 162-174. https://doi.org/10.1007/s13355-014-0318-3

Furmanowa, M., Kropczynska, D., Zobel, A., Glowniak, K., Oledzka, H., Jozefowicz, J., Sahajdak, A., \& Jozetczyk, K. (2002). Influence of water extracts from the surface of two yew (Taxus) species on mites (Tetranychus urticae). J. Appl. Toxicol., 22, 107-109. https://doi.org/10.1002/jat.834

George, D. R., Finn, R. D., Graham, K. M., \& Sparagano, O. A. E. (2014). Present and future potential of plant-derived products to control arthropods of veterinary and medical significance. Parasit Vectors, 7, 28. https://doi.org/10.1186/1756-3305-7-28 
Girardi, F. A., Tonial, F., Chini, S. O., Sobottka, A. M., Scheffer-Basso, S. M., \& Bertol, C. D. (2014). Phytochemical profile and antimicrobial properties of Lotus spp. (Fabaceae). An. Acad. Bras. Ciênc., 86(3), Rio de Janeiro. https://doi.org/10.1590/0001-3765201420130220

Govindachari, T. R., Gopalajrishnan, G., \& Suresh, G. (1999). Triterpenoidal constituents of an aqueous extract from neem kernels. Fitoterapia, 70, 558-560. https://doi.org/10.1016/S0367-326X(99)00087-8

Jazzar, C., \& Abou-Fakhr Hammad, E. (2003). The efficacy of enhanced aqueous extracts of Melia azedarach leaves and fruits integrated with the Camptotylus reuteri releases against the sweetpotato whitefly nymphs. Bull. Insectology, 56(2), 269-275.

Khajehali, J., Van Leeuwen, T., \& Tirry, L. (2009). Susceptibility of an organophosphate resistant strain of the two-spotted spider mite (Tetranychus urticae) to mixtures of bifenazate with organophosphate and carbamate insecticides. Experimental and Applied Acarology, 49(3), 185-192. https://oi.org/10.1007/ s10493-009-9261-3

Khater, H. F. (2012). Ecosmart Biorational Insecticides: Alternative Insect Control Strategies, Insecticides. In F. Perveen (Ed.), Advances in Integrated Pest Management. InTech. Retrieved from http://www.intechopen. com/books/insecticides-advances-in-integrated-pestmanagement/ecosmart-biorational-insecticides-alternati ve-insect-control-strategies

Mishra, G., Jawla, S., \& Srivastava, V. (2013). Melia Azedarach: A Review. Int. J. Med. Chem. Analysis, 3(2), 53-56.

Pascual-Villalobos, M. J., \& Ballesta-Acosta, M. C. (2003) Chemical variation in an Ocimum basilicum germplasm collection and activity of the essential oils on Callosobruchus maculatus. Biochem. System Ecol. 31, 673-679. https://doi.org/10.1016/S0305-1978(02)00183-7

Tsagkarakou, A., Pasteur, N., Cuany, A., Chevillon, C., \& Navajas, M. (2002). Mechanisms of resistance to organophosphates in Tetranychus urticae (Acari: Tetranychidae) from Greece. Insect Biochemistry and Molecular Biology, 32, 417-424. https://doi.org/10.1016/S0965-1748(01)00118-7

Wink, M. (2015). Modes of Action of Herbal Medicines and Plant Secondary Metabolites. Review. Medicines 2, 251-286. https://doi.org/10.3390/medicines2030251

\section{Copyrights}

Copyright for this article is retained by the author(s), with first publication rights granted to the journal.

This is an open-access article distributed under the terms and conditions of the Creative Commons Attribution license (http://creativecommons.org/licenses/by/4.0/). 